3. Cazorla C, Enea M, Lucht F, Raoult D. First isolation of Rickettsia slovaca from a patient, France. Emerg Infect Dis. 2003;9:135. http://dx.doi.org/10.3201/eid0901.020192

4. Oteo JA, Ibarra V, Blanco JR, Martínez de Artola V, Márquez FJ, Portillo A, et al. Dermacentor-borne necrosis erythema and lymphadenopathy: clinical and epidemiological features of a new tick-borne disease. Clin Microbiol Infect. 2004;10:327-31. http://dx.doi.org/10.1111/j.1198-743X.2004.00782.x

5. Portillo A, Ibarra V, Santibáñez S, Pérez-Martínez L, Blanco JR, Oteo JA. Genetic characterisation of ompA, ompB and gltA genes from Candidatus Rickettsia rioja. Clin Microbiol Infect. 2009;15(Suppl 2):307-8. http://dx.doi.org/10.1111/ j.1469-0691.2008.02250.x

6. Pérez-Pérez L, Portillo A, Allegue F, Zulaica A, Oteo JA, Caeiro JL, et al. Dermacentor-borne necrosis erythema and lymphadenopathy (DEBONEL): a case associated with Rickettsia rioja. Acta Derm Venereol. 2010;90:214-5. http://dx.doi.org/10.2340/00015555-0801

7. Dubourg G, Socolovschi C, Del Giudice P, Fournier PE, Raoult D Scalp eschar and neck lymphadenopathy after tick bite: an emerging syndrome with multiple causes. Eur J Clin Microbiol Infect Dis. 2014;33:1449-56. http://dx.doi.org/10.1007/s10096-014-2090-2

8. Oteo JA, Portillo A. Tick-borne rickettsioses in Europe. Ticks Tick Borne Dis. 2012;3:271-8. http://dx.doi.org/10.1016/ j.ttbdis.2012.10.035

9. Shah SS, McGowan JP. Rickettsial, ehrlichial and Bartonella infections of the myocardium and pericardium. Front Biosci. 2003; 8:e197-201. http://dx.doi.org/10.2741/995

10. Lebrun-Vignes B, Kreft-Jais C, Castot A, Chosidow O. Comparative analysis of adverse drug reactions to tetracyclines: results of a French national survey and review of the literature. Br J Dermatol. 2012;166:1333-41. http://dx.doi.org/10.1111/ j.1365-2133.2012.10845.x

Address for correspondence: José Tiago Silva, Unidad de Enfermedades Infecciosas, Hospital Universitario "12 de Octubre," Centro de Actividades Ambulatorias, Planta 2a, Bloque D. Avda de Córdoba, s/n. Postal Code 28041, Madrid, Spain; email: j.tiago.silva@hotmail.com

\section{Parainfluenza Virus 5 as Possible Cause of Severe Respiratory Disease in Calves, China}

\author{
Ye Liu, ${ }^{1}$ Nan Li, ${ }^{1}$ Shoufeng Zhang, Fei Zhang, \\ Hai Lian, Rongliang Hu
}

Author affiliations: Laboratory of Epidemiology and Key Laboratory of Jilin Province for Zoonosis Prevention and Control, Academy of Military Medical Sciences, Changchun, China

DOI: http://dx.doi.org/10.3201/eid2112.141111

To the Editor: Parainfluenza virus 5 (PIV5), family Paramyxoviridae, genus Rubulavirus, was previously known as simian virus 5 because of its discovery in primary

${ }^{1}$ These authors contributed equally to this article. monkey kidney cells in 1954 (1). PIV5 was later isolated from various hosts, including humans, dogs, pigs, cats, and rodents. The neutralizing antibody for PIV5 is detectable in symptomatic and asymptomatic humans; thus, its association with human disease remains controversial (2). In addition, previous studies have not documented illness in infected animals, except kennel cough in dogs $(1,3)$. Isolation of PIV5 from cattle has not previously been reported.

Since 2012, an infectious respiratory disease has been prevalent in weaning calves $(\approx 10 \mathrm{~d}$ to 2 mo of age) in Baicheng City, Jilin Province, China. Initial clinical signs included secretion of clear nasal mucus, anorexia, sluggishness, and loss of body weight. After $10-20 \mathrm{~d}, \approx 10 \%$ of the sick calves died of dyspnea and interstitial pneumonia. Farmers observed that $80 \%-90 \%$ of calves in the affected farms demonstrated clinical signs, but most recovered. All attempts of local veterinarians to treat the animals with various chemical compounds and antimicrobial drugs failed. The disease persists throughout the year but occurs mainly during spring (from February through March), which has resulted in substantial economic losses in the cattle industry.

To identify the causative agent of the disease, we tested 15 lung samples from calves that had died and 10 lung samples from healthy calves that were slaughtered for serum products (all from 1 farm). The samples were homogenized in phosphate-buffered saline and analyzed by using electron microscopy. Paramyxovirus-like particles were identified in the tissues of sick calves. Reverse transcription PCR with the generic primers for the paramyxovirus polymerase gene was performed (4).

Of the 25 calf specimens, the 15 samples from the sick calves were positive by reverse transcription PCR, and amplicons of the expected size were obtained and sequenced. The generated sequences were closely related to the PIV5 sequences available from GenBank, particularly to sequences of the recently identified KNU-11 and SER viruses in pigs $(5,6)$.

The suspensions of lung tissue from sick calves were purified by centrifugation at $12,000 \times \mathrm{g}$ for $5 \mathrm{~min}$, and 0.2 $\mathrm{mL}$ of the supernatant was added to a Vero cell monolayer in a $25-\mathrm{cm}^{2}$ cell culture flask (EasyFlasks; Thermo Fisher Scientific, Odense, Denmark). After virus adsorption for 1 $h$ at $37^{\circ} \mathrm{C}$, the cell monolayer was rinsed with phosphatebuffered saline $(\mathrm{pH} 7.4)$ and then incubated in Dulbecco minimal essential medium $/ 2 \%$ newborn calf serum at $37^{\circ} \mathrm{C}$ in a $5 \% \mathrm{CO}_{2}$-humidified incubator. The infected cells were serially passaged every 3 days at $37^{\circ} \mathrm{C}$ and detected by using monoclonal antibody against SV5 (AbD Serotec; BioRad, Kidlington, UK) by indirect fluorescent antibody test (7). A PIV5 strain was isolated in the cell culture and designated PIV5-BC14 (BC14 stands for Baicheng City 2014).

For amplification and analysis of the full-length viral genome, 13 pairs of primers covering overlapping 


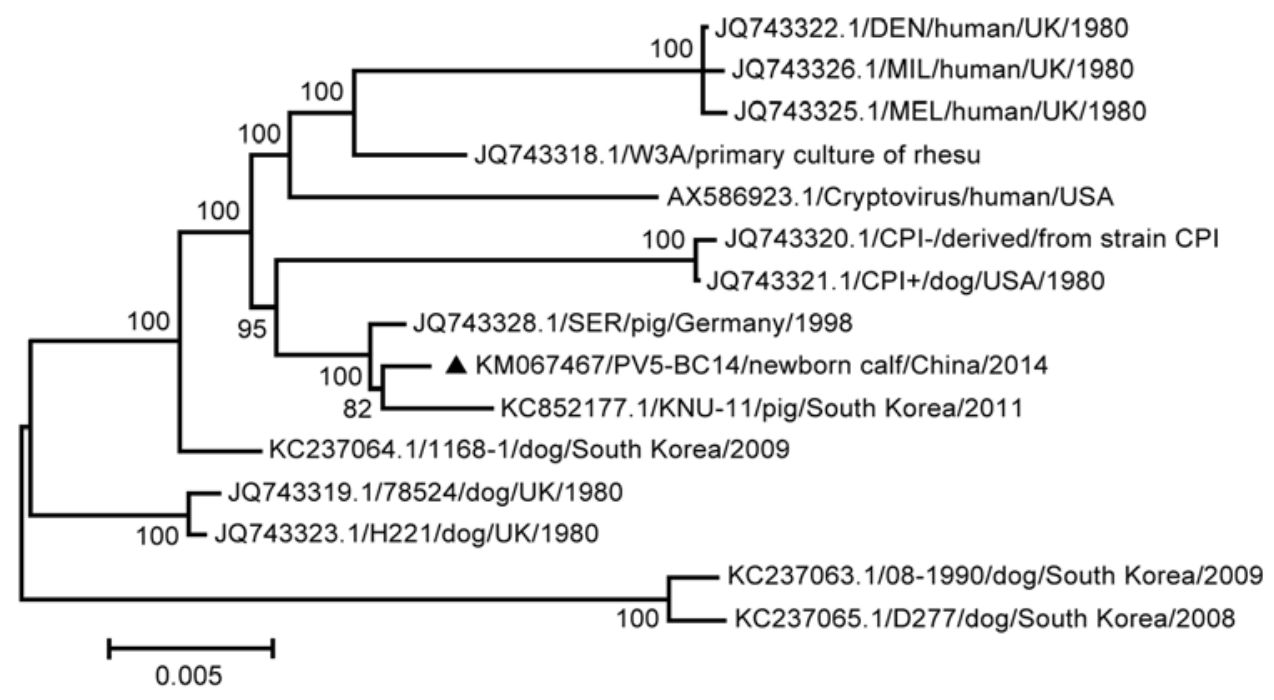

Figure. Maximum-likelihood phylogenetic tree based on the complete genome sequences of parainfluenza virus 5 (PIV5). The black triangle indicates isolate PIV5-BC14 (Baicheng City 2014). Scale bar indicates nucleotide substitutions per site.

fragments of the genome were designed on the basis of the sequence of the PIV5 isolate KNU-11 (8). The $3^{\prime}$ and $5^{\prime}$ termini of the genome were resolved by using the $3^{\prime}$ and $5^{\prime}$ Full RACE Kit (TaKaRa Biotechnology Co., Ltd., Dalian, China). The PIV5-BC14 genome (GenBank accession no. KM067467) was $15,246 \mathrm{nt}$ with coding and untranslated regions at the same positions as in other PIV5 isolates (9). However, comparison of this genome with 15 available full-length genomes of PIVs revealed that $18 \mathrm{nt}$ substitutions, resulting in 9 aa changes, are found only in PIV5BC14. Among these 9 aa changes, 5 (at positions 303, 634, 1054, 1722, and 1773) are present in an RNA-dependent RNA polymerase protein, 2 in a phosphoprotein (at positions 43 and 332), 1 in a nucleoprotein (at position 75), and 1 in a hemagglutinin-neuraminidase (at position 322).

The highest nucleotide identity (99.72\%/99.52\%) was observed between PIV5-BC14 and porcine PIV, particularly with the SER virus isolate. This observation was confirmed after construction of a phylogenetic tree based on the 15 available nucleotide sequences of the full-length genomes (Figure). The analysis was carried out by using the maximum-likelihood method in MEGA 5.0 (10), and the reliability of tree topology was evaluated through bootstrapping with 1,000 replicates.

Although the pathogenic role of PIV5 infections in cattle remains unknown, no PIV5 RNA was found in any apparently healthy cattle from the same farm. This result suggests a strong relationship between the identified virus and the disease.

This research was funded by the China National "973" Program (approval no. 2011CB504700).

Drs. Liu and Li are both research fellows at the Academy of Military Medical Sciences (China). Their research interests include rabies epidemiology and vaccines. More recently, they are both working on emerging and reemerging infectious diseases in animals in China.

\section{References}

1. Hsiung GD. Parainfluenza-5 virus. Infection of man and animal. Prog Med Virol. 1972;14:241-74.

2. Zhang L, Collins PL, Lamb RA, Pickles RJ. Comparison of differing cytopathic effects in human airway epithelium of parainfluenza virus 5 (W3A), parainfluenza virus type 3, and respiratory syncytial virus. Virology. 2011;421:67-77. http://dx.doi.org/10.1016/j.virol.2011.08.020

3. Chatziandreou N, Stock N, Young D, Andrejeva J, Hagmaier K, McGeoch DJ, et al. Relationships and host range of human, canine, simian and porcine isolates of simian virus 5 (parainfluenza virus 5). J Gen Virol. 2004;85:3007-16. http://dx.doi.org/10.1099/ vir.0.80200-0

4. Tong S, Chern SW, Li Y, Pallansch MA, Anderson LJ. Sensitive and broadly reactive reverse transcription-PCR assays to detect novel paramyxoviruses. J Clin Microbiol. 2008;46:2652-8. http://dx.doi.org/10.1128/JCM.00192-08

5. Lee YN, Park CK, Kim S, Lee DS, Shin JH, Lee CH. Characterization in vitro and in vivo of a novel porcine parainfluenza virus 5 isolate in Korea. Virus Res. 2013;178:423-9. http://dx.doi.org/10.1016/j.virusres.2013.09.010

6. Heinen E, Herbst W, Schmeer N. Isolation of a cytopathogenic virus from a case of porcine reproductive and respiratory syndrome (PRRS) and its characterization as parainfluenza virus 2. Arch Virol. 1998;143:2233-9. http://dx.doi.org/10.1007/ s007050050454

7. Randall RE, Young DF, Goswami KK, Russell WC. Isolation and characterization of monoclonal antibodies to simian virus 5 and their use in revealing antigenic differences between human, canine and simian isolates. J Gen Virol. 1987;68:2769-80. http://dx.doi.org/10.1099/0022-1317-68-11-2769

8. Lee YN, Lee CH. Complete genome sequence of a novel porcine parainfluenza virus 5 isolate in Korea. Arch Virol. 2013;158: 1765-72. http://dx.doi.org/10.1007/s00705-013-1770-z

9. Rima BK, Gatherer D, Young DF, Norsted H, Randall RE, Davision AJ. Stability of the parainfluenza virus 5 genome revealed by deep sequencing of strains isolated from different hosts and following passage in cell culture. J Virol. 2014;88:3826-36. http://dx.doi.org/10.1128/JVI.03351-13 
10. Tamura K, Peterson D, Peterson N, Stecher G, Nei M, Kumar S. MEGA5: Molecular evolutionary genetics analysis using maximum likelihood, evolutionary distance, and maximum parsimony methods. Mol Biol Evol. 2011;28:2731-9. http://dx.doi.org/ $10.1093 / \mathrm{molbev} / \mathrm{msr} 121$

Address for correspondence: Rongliang $\mathrm{Hu}$, Academy of Military

Medical Sciences, 666 Liuying West Rd, Jingyue Economy Development Zone, Changchun 130122, China; email: ronglianghu@hotmail.com

\section{Alternative Routes of Zoonotic Vaccinia Virus Transmission, Brazil}

\section{Galileu B. Costa, lara A. Borges, Pedro A. Alves, Júlia B. Miranda, Ana Paula M.F. Luiz, Paulo C.P. Ferreira, Jônatas S. Abrahão, Elizabeth C. Moreno, Erna G. Kroon, Giliane de Souza Trindade}

\author{
Author affiliations: Universidade Federal de Minas Gerais, \\ Belo Horizonte, Minas Gerais, Brazil (G.B. Costa, I.A. Borges, \\ P.A. Alves, J.B. Miranda, A.P.M.F. Luiz, P.C.P. Ferreira, \\ J.S. Abrahão, E.G. Kroon, G. de Souza Trindade); \\ Fundação Hemominas. Belo Horizonte (E.C. Moreno) \\ DOI: http://dx.doi.org/10.3201/edit2112.141249
}

To the Editor: Vaccinia virus (VACV) causes exanthematous disease (bovine vaccinia) in Brazil. Outbreaks of this disease in humans have been reported since the late 1990s and have spread throughout Brazil (1). Natural human infections with VACV occur by close contact with infected cattle during milking. Lesions can spread to secondary body sites (forearms, arms, and face). Thus, personto-person transmission occurs (1).

Moreover, virus can persist in household environments, remain infectious, and be transmitted by fomites (2). Although raw milk and cheese are potential sources of infection, no clinical cases have been associated with this transmission route $(3,4)$. Data for person-to-person transmission in Brazil are scarce, but person-to-person transmission was recently reported (5). We report a possible case of person-to-person transmission of VACV.

This study was approved by the Research Ethics Committee of Universidade Federal de Minas Gerais (registration protocol FR-413704). In September 2012, during a serologic survey in a rural area of Serro City $\left(18^{\circ} 36^{\prime} 17^{\prime \prime} \mathrm{S}\right.$, $43^{\circ} 22^{\prime} 46^{\prime \prime} \mathrm{W}$ ), Minas Gerais, Brazil (online Technical Appendix Figure, panel A, http://wwwnc.cdc.gov/EID/ article/21/12/14-1249-Techapp1.pdf), blood samples were obtained from a family of 5 persons (father, mother, and 3 daughters). The father and mother were 48 and 53 years of age, respectively, and had been vaccinated against smallpox. They reported contact with cows and horses (online Technical Appendix Table 1). Only the father had milked cows. The 3 daughters $(13,13$, and 14 years of age) did not engage in any exposure activity. However, all family members had consumed raw milk and cheese.

Bovine vaccinia lesions were observed on the hand of the father (online Technical Appendix Figure, panel B). In 2011, he had vesicular disease (no laboratory diagnosis) with clinical and epidemiologic features (lesions) suggestive of bovine vaccinia on his hands and forearms and systemic symptoms (fever, headache, malaise, myalgia, lymphadenopathy, and abdominal pain). His symptoms were mild and without any systemic clinical features. Two lesions developed on his hands and dried swab samples were collected from both lesions. Swab samples were processed as described (2) and used for virus isolation and molecular diagnosis.

On the basis of previous studies that detected viral DNA in clinical samples from persons with bovine vaccinia (1), we used a quantitative PCR to amplify the $v g f$ and $h a$ genes of VACV (3-5), a standard PCR to detect the $h a$ gene (3-5), and a seminested PCR to detect the ati gene (F.L. Assis, unpub. data). Serum samples were used for detection of virus-neutralizing antibodies (orthopoxvirus $50 \%$ plaque-reduction neutralization test) and molecular diagnostic studies (1). Virus isolation was attempted in Vero cells and chorioallantoic membrane. All results were negative.

The $50 \%$ plaque-reduction neutralization test showed that the father, mother, and 14-year-old daughter had neutralizing antibodies against orthopoxvirus (titers 800, 3,200, and 800 neutralizing units $/ \mathrm{mL}$, respectively). All family members had positive results by molecular diagnostic test for $\geq 1$ virus gene (online Technical Appendix Table 1). To rule out infection with parapopoxvirus, a complementary PCR (6) was also performed, and all family members had negative results.

Quantitative PCR products for the $h a$ gene from 3 virus-positive samples were sequenced in both directions in triplicate (Mega BACE Sequencer; GE Healthcare, Little Chalfont, UK). Sequences were aligned by using ClustalW (http://www.genome.jp/tools/clustalw/) and MEGA4.1 (http://www.megasoftware.net/) and showed 100\% identity with each other (Figure). A phylogenetic tree was constructed by using the neighbor-joining method and 1,000-bootstrap replicates in the Tamura-3 parameter model (MEGA4.1). Sequences were grouped with VACV group 2 isolates. Sequences obtained were deposited in GenBank under accession nos. KP889223-5).

In Brazil, outbreaks of bovine vaccinia are associated with rural environments. However, some clinical and 